\section{Effects of cellular redox balance on induction of apoptosis by eicosapentaenoic acid in HT29 colorectal adenocarcinoma cells and rat colon in vivo}

P Latham, E K Lund, J C Brown, I T Johnson

\begin{abstract}
Background and aims-Epidemiological evidence suggests $n-3$ polyunsaturated lipids may protect against colorectal neoplasia. Consumption of fish oil modulates crypt cytokinetics in humans, and crypt apoptosis in animal models. To explore these effects, we investigated involvement of caspase enzymes and cellular redox balance in the induction of apoptosis by eicosapentaenoic acid (EPA) in HT29 cells, and in rat colon in vivo.

Methods-Survival of HT29 cells grown with EPA in the presence of caspase inhibitors, antioxidants, or buthionine sulphoximine, an inhibitor of glutathione neosynthesis, was determined. The effects of EPA enriched fish oil and glutathione depletion on apoptosis in rat colon were assessed using microdissected crypts.

Results-Treatment of HT29 cells with EPA reduced viable cell number and activated caspase 3 , prior to cell detachment. Antioxidants and caspase inhibitors blocked HT29 cell death whereas glutathione depletion increased it. Rats fed fish oil had higher crypt cell apoptosis than those fed corn oil, and glutathione depletion enhanced this effect.

Conclusions-Incorporation of EPA into colonic epithelial cell lipids increases apoptosis. The results of this study, using both an animal and cell line model, support the hypothesis that this effect is mediated via cellular redox tone, and is sensitive to glutathione metabolism. The data suggest a mechanism whereby polyunsaturated fatty acids may influence the susceptibility of colorectal crypt cells to induction or progression of neoplasia. (Gut 2001;49:97-105)
\end{abstract}

Keywords: eicosapentaenoic acid; apoptosis; glutathione; caspase; redox; colorectal cancer; rat

Institute of Food

Research, Norwich

Research Park, Colney,

Norwich NR4 7UA, UK

P Latham

E K Lund

J C Brown

I T Johnson

Correspondence to: E K Lund.

liz.lund@bbsrc.ac.uk

Accepted for publication 29 January 2001

The colonic mucosa is a rapidly proliferating tissue in which cell production is balanced by exfoliation from the mucosal surface, and by a much smaller component of cell loss via apoptosis within the crypts. Although the latter is a relatively rare event, it may play an important role in the prevention of neoplasia because it provides a route for the elimination of stem cells carrying potentially procarcinogenic mutations. The possible significance of this mechanism for the prevention of colorectal cancer is illustrated by the non-steroidal antiinflammatory drug (NSAID) sulindac which induces apoptosis in colorectal cancer cells in vitro, ${ }^{1}$ causes regression of aberrant crypt foci in humans, ${ }^{2}$ and reduces growth of polyps in patients with familial adenomatous polyposis. ${ }^{3}$ Dietary components that induce similar effects could be of value in the control of colorectal neoplasia. In common with sulindac and other NSAIDS, certain polyunsaturated fatty acids (PUFA) kill tumour cells in vitro, ${ }^{4}$ and inhibit the growth of tumours in animal models. ${ }^{56}$ Marine oils rich in PUFA also exert potentially beneficial effects on crypt cytokinetics in the colorectal mucosa of patients with adenomatous polyps. ${ }^{7}$ We and others have previously shown that fish oil increases the number of cells undergoing apoptosis in rat colonic crypts. ${ }^{89}$ This effect is enhanced in rats given the carcinogen 1,2,-dimethyl hydrazine hydrochloride $(\mathrm{DMH})$, and under these conditions high levels of crypt cell apoptosis are associated with a reduced number of aberrant crypt foci. ${ }^{8}$ The active components of marine oils are thought to be the n-3 PUFA eicosapentaenoic acid (EPA) and docosahexaenoic acid, but the mechanisms of their effects on dividing cells are not clear.

The molecular basis of apoptosis in colonic epithelial cells is not well characterised but as in other tissues, apoptosis induced by a variety of different stimuli, including butyrate, ${ }^{10}$ topoisomerase inhibitors, ${ }^{11}$ and detachment from the substratum, ${ }^{12}$ involves activation of caspases. This family of specific cysteine proteases is thought to execute cell death by cleavage of a number of target substrates, including cytoskeletal and associated proteins, kinases, and DNA related enzymes. ${ }^{13}$ In an earlier study with HT29 cells we showed that incorporation of EPA was followed by increased loss of cell adhesion. ${ }^{14}$ Detachment from the extracellular matrix is a characteristic feature of colonic epithelial cell lines undergoing apoptosis in vitro ${ }^{15}$ and in vivo. ${ }^{16}$ In our in vitro model, incorporation of the vital dye neutral red is used to
Abbreviations used in this paper: NSAID, non-steroidal anti-inflammatory drug; PUFA, polyunsaturated fatty acids; EPA, eicosapentaenoic acid; DMH, 1,2,-dimethyl hydrazine hydrochloride; DMEM, Dulbecco's modified Eagle's medium; FAMES, fatty acid methyl esters; PBS, phosphate buffered saline; GSH, reduced glutathione; GSSG, oxidised glutathione; GSX, intracellular glutathione; $\mathrm{BSO}$, buthionine sulphoximine; BAF,

Boc-Asp(Ome)-FMK; pNA, p-nitroanilide; Nac, $\mathrm{N}$-acetylcysteine; CO, corn oil; FO, fish oil. 
quantify the number of viable adherent cells in the cell culture system. Cells that become detached following exposure to EPA exhibit characteristic features of apoptotic cell death such as condensed chromatin and DNA laddering, but there are no such phenotypic markers detectable in adherent cells. ${ }^{14}$ In the present study we have demonstrated for the first time a role for caspases in induction of cell death by long chain PUFA and shown that activation of this system begins prior to detachment of the cells from the substratum.

Previous studies suggest that peroxidation of cellular lipids and the production of free radicals may be primary initiators of apoptosis in a number of systems. ${ }^{16}$ Hawkins and colleagues ${ }^{17}$ recently showed that PUFA induced apoptosis in pancreatic and leukaemic cell lines, the level of cytotoxicity being proportional to the number of constituent double bonds in the fatty acid. Similarly, orally administered PUFAs have been shown to suppress the growth of human mammary carcinomas in a nude mouse model, to a degree that correlates with the production of lipid peroxidation products. ${ }^{18}$ Reactive oxygen species have also been implicated in the apoptotic response to stress ${ }^{19}$ and cellular senescence ${ }^{20}$ in the small intestine. On the other hand, recent work of Chinery and colleagues ${ }^{21} 22$ suggests that treatment with antioxidants can induce apoptosis in colorectal cancer cells in vitro, and enhance inhibition of tumour growth by cytotoxic agents in vivo. In the present study we observed the opposite effect in that the initiation of caspase mediated cell death in colonic epithelial cells was prevented by antioxidants in vitro. We extended these studies to the rat colon in vivo, and showed that, as in the cultured tumour cells, there was amplification of crypt cell apoptosis following incorporation of EPA from dietary fish oil into epithelial cell phospholipids, and this effect was enhanced by a reduction in cellular glutathione levels.

\section{Materials and methods}

CELL CULTURE

The colonic adenocarcinoma cell line HT29 was obtained from the European Collection of Cell Cultures (Salisbury, UK). HT29 cells were grown in Dulbecco's modified Eagle's medium (DMEM; Sigma) supplemented with $5 \%$ heat inactivated fetal calf serum (Sigma), $2 \mathrm{mM}$ glutamine, 50 units $/ \mathrm{ml}$ penicillin, and $50 \mu \mathrm{g} / \mathrm{ml}$ streptomycin (all from Imperial Laboratories, Andover, UK). Cells were grown at $37^{\circ} \mathrm{C}$, in $5 \% \mathrm{vol} / \mathrm{vol} \mathrm{CO}_{2}$ in a humidified atmosphere, and harvested using phosphate buffered saline (PBS) containing $0.05 \% \mathrm{wt} / \mathrm{vol}$ trypsin and $0.02 \% \mathrm{wt} / \mathrm{vol}$ EDTA (Imperial Laboratories). EPA (cis, 5, 8, 11, 14, 17) was purchased from Sigma in sealed ampoules containing $25 \mathrm{mg}$. The contents were dissolved in ethanol to give a $25 \mathrm{mg} / \mathrm{ml}$ stock solution, and crimp sealed in an amber vial under nitrogen. The EPA-ethanol mix was further diluted in DMEM to give final concentrations of 15 , 30 , and $45 \mu \mathrm{M}$. EPA has previously been shown by us to cause apoptosis in HT29 cells at these concentrations $^{14}$ which are comparable with levels of approximately $65 \mu \mathrm{M}$ observed in the plasma of unsupplemented human subjects, and substantially lower than concentrations of about $400 \mu \mathrm{M}$ achieved in subjects supplemented with $3 \mathrm{~g}$ of fish oil per day for 18 weeks. ${ }^{23}$ The final concentration of ethanol was approximately $0.06 \%$ vol, a level which was found to have no effect on cell phenotype in control experiments.

\section{CELL VIABILITY ASSAY}

The effects of EPA and other treatments on the survival and proliferation of HT29 cells were quantified by measuring the relative numbers of viable adherent cells after culture using a neutral red incorporation assay applied to 96 well plates. ${ }^{24}$ Cells were seeded into Nunclon 96 well plates (Fisher, Loughborough, UK) at a density of $23 \times 10^{3}$ cells per well, allowed 24 hours to adhere, and treated with media containing 15, 30, and $45 \mu \mathrm{M}$ EPA for 24 or 48 hours, with or without antioxidants or caspase inhibitors, as described below. At least 16 replicate wells were used for each treatment. The relative numbers of viable adherent cells were determined at the end of each experiment by incubation for three hours with $50 \mu \mathrm{M}$ neutral red (3-amino-7-dimethylamine-2-methylphenozine hydrochloride; Sigma) diluted in DMEM. Plates were then drained, fixed in $40 \%$ (vol $/ \mathrm{vol}$ ) formaldehyde $/ 10 \%$ (wt $/ \mathrm{vol}$ ) calcium chloride hexahydrate (BDH, Poole, UK) for 30 seconds, washed three times in PBS, and air dried. The neutral red was solubilised from the fixed cells by addition of $200 \mu \mathrm{l}$ of ethanol $(50 \%) /$ acetic acid (1\%) per well, and absorbance was measured at $550 \mathrm{~nm}$ using a Dynatech MR5000 automated plate reader (Dynatech Lab Inc, Alexandria, Virginia, USA). In separate experiments absorbance due to neutral red was found to be linearly proportional to the numbers of adherent HT29 cells over the range $1 \times 10^{3}-50 \times 10^{3}$ cells per well $\left(r^{2}=0.98\right.$; data not shown). Results were expressed as a percentage of the absorbance values obtained for control cultures.

\section{CELLULAR LIPID COMPOSITION}

Total lipids were extracted from $10^{7}$ HT29 cells or from isolated mucosal crypts (see below) according to the method of Bligh and Dyer. ${ }^{25}$ Chloroform extracts were dried under $\mathrm{N}_{2}(\mathrm{~g})$ at $40^{\circ} \mathrm{C}$ and stored at $-20^{\circ} \mathrm{C}$ in glass vials. The polar phospholipid fraction was extracted using a Sep-Pak column (Waters Corporation, Milford, Massachusetts, USA) according to the manufacturer's instructions. The methanol washes containing the polar phospholipids were collected, and dried under $\mathrm{N}_{2}$ (g) at $50^{\circ} \mathrm{C}$ before storage. Conversion of extracted total lipid and phospholipid to fatty acid methyl esters (FAMES) was performed by a cold methylation procedure. ${ }^{26}$ Changes in fatty acid composition of the whole cell and phospholipid fractions associated with treatment with EPA were assessed by gas chromatographic analysis using a Hewlett Packard 6890 gas chromatograph, equipped with a flame ionisation detector and split injector. Individual FAMES were identified by comparison of retention times 
with those of standards comprising all of the major fatty acids from $\mathrm{C} 12$ to $\mathrm{C} 24(\mathrm{Nu}-\mathrm{Check}$ Prep Inc., Elysian, Minnesota, USA).

ACTIVATION AND INHIBITION OF CASPASES

Caspase 3-like protease activity (DEVD specific) was assessed in adherent HT29 cells grown in $80 \mathrm{~cm}^{2}$ flasks with $0,15,30$, or $45 \mu \mathrm{M}$ EPA for 24 or 48 hours. DEVDase activity was assayed in cell pellets $\left(2 \times 10^{6}\right.$ cells $)$ using a colorimetric kit (Clontech, Basingstoke, UK) which detects cleavage of the chromophore p-nitroanilide (pNA) from a consensus DEVD tetrapeptide sequence. The DEVDase inhibitor Z-DEVD-FMK (Calbiochem, Nottingham, UK) was added to one treatment sample as a negative control to confirm that liberation of pNA was DEVDase specific. Positive control cells were treated with $25 \mu \mathrm{M} \mathrm{C}_{2}$ ceramide for three hours (Calbiochem) or UV light for 30 minutes $\left(12000 \mathrm{~J} / \mathrm{cm}^{2}\right)$; negative control cells were incubated in the absence of EPA. EPA and DEVD-pNA were also incubated together in a reaction (for $1,12,24$, and 48 hours) to confirm that EPA alone had no capacity to cleave pNA from the DEVD tetrapeptide.

For caspase inhibition studies, cells were incubated with $30 \mu \mathrm{M}$ EPA in 96 well plates in the presence of cell permeable caspase inhibitors for 24 or 48 hours. Caspase inhibitors (Calbiochem) included Z-DEVD-FMK (caspase 3), IETD-CHO (caspase 8), Z-VADFMK (broad spectrum), and Boc-D(OMe)FMK (BAF; broad spectrum). Cell viability was assessed as described above.

\section{ANTIOXIDANT STUDIES}

To establish if oxidative processes were involved in EPA induced reductions in cell viability, HT29 cells were cultured for 48 hours with $\operatorname{EPA}(0,15,30$, or $45 \mu \mathrm{M})$ in 96 well plates in the presence of the antioxidants $\mathrm{N}$-acetylcysteine (Nac $1 \mathrm{mM}$; Calbiochem), ebselen ( $40 \mu \mathrm{M}$; Calbiochem), or U74389G (5 $\mu \mathrm{M}$; Calbiochem). Media were refreshed with EPA and antioxidants after 24 hours and cell viability was determined as described above.

DEPLETION OF INTRACELLULAR GLUTATHIONE

The effects of reduced glutathione (GSH) depletion on the response of HT29 cells to treatment with EPA were investigated using DL-buthionine sulphoximine (BSO), a specific $\gamma$-glutamyl-cysteine synthetase inhibitor that suppresses GSH neosynthesis. To determine the effect of BSO on cellular GSH levels, HT29 cells were grown in $80 \mathrm{~cm}^{2}$ flasks $\left(10^{7}\right.$ cells per flask) with $30 \mu \mathrm{M}$ EPA $+100 \mu \mathrm{M}$ BSO for 48 hours, washed twice with PBS, and collected into microfuge tubes as pellets of $10^{7}$ cells. Total $\mathrm{GSH}$ (reduced GSH and oxidised GSH (GSSG)) was assayed as intracellular glutathione (GSX) units according to the enzymatic recycling method of Baker and colleagues ${ }^{27}$ which was adapted for an automated biochemistry analyser inhouse (Cobas Mira; Roche, Welwyn, UK). For viability studies, cells were cultured in 96 well plates for 24 or 48 hours in media containing EPA $(0-45 \mu \mathrm{M}), \mathrm{EPA}+100$ $\mu \mathrm{M} \mathrm{BSO}$, or EPA+BSO+ebselen $(40 \mu \mathrm{M})$ for 24 or 48 hours, and cell viability assayed as described previously.

\section{IN VIVO STUDY}

To explore the role of GSH metabolism in induction of apoptosis by n-3 fatty acids in vivo, 72 male Wistar rats $(125-150 \mathrm{~g})$ were housed individually in polypropylene containers with wire bottoms and tops in a temperature $\left(21^{\circ} \mathrm{C}\right)$ and humidity controlled animal unit with a daily 12 hour light-dark cycle. Prior to the start of the experiment, rats were allowed to consume a semisynthetic powdered diet ad libitum (g/kg: starch 280; sucrose 380; casein 200; corn oil 80; balanced mineral and vitamin mix 60). After four weeks rats were assigned randomly to one of four treatment groups of 18. Two groups continued to receive the basal diet containing corn oil (CO) and two received a similar diet in which corn oil was entirely replaced with fish oil (FO: $96.7 \%$ triacylglycerols of which $18.7 \%$ C20:5 and 8.0\% C22:6; Callanish, Breasclete, UK). One CO and one FO group received distilled water ad libitum for the duration of the experiment and the remaining groups (CO-BSO; FO-BSO) received distilled water supplemented with BSO (Sigma) at a final concentration of $5 \mathrm{mM}$. Weight gain and food and water intake were measured every 24 or 48 hours. After 24 hours, 48 hours, and one week, six rats from each group were killed by intraperitoneal injection of pentabarbitone sodium $(1.0 \mathrm{ml})$ followed by cervical dislocation under deep anaesthesia. The entire colon was removed via a midline abdominal incision and tissues were processed as described below.

To determine the effects of the experimental treatments on mucosal lipids, a parallel experiment was performed using a further 20 male Wistar rats assigned to four groups of five each, and fed $\mathrm{CO}$ or FO, with or without $5 \mathrm{mM}$ BSO in their drinking water, for seven days. They were then killed, and intact colonic crypts were isolated for lipid analysis as described for HT29 cells.

ANALYSIS OF CRYPT CELL PROLIFERATION AND APOPTOSIS

The isolated colon was everted on a $3 \mathrm{~mm}$ diameter metal rod and cut in half. Full thickness tissue samples (approximately $5 \mathrm{~mm}$ ) from the distal end were fixed in ethanol:acetic acid (75:25) and stored at $4^{\circ} \mathrm{C}$ in 2 dram glass vials. For analysis of numbers and spatial distribution of apoptotic and mitotic crypt cells, tissue samples were rehydrated in distilled water, hydrolysed in $1 \mathrm{M} \mathrm{HCl}$ for seven minutes at $60^{\circ} \mathrm{C}$, and stained with Fuelgen's reagent. Tissues were microdissected under low power microscopy to yield thin strips of crypts which were gently squashed beneath a coverslip and viewed under a light microscope $(\times 400)$. The length of each crypt was determined by comparison with a calibrated linear eyepiece graticule (Nikon UK Ltd), apoptotic and mitotic cells were identified by morphological features as previously described, ${ }^{8}$ and their positions were recorded and allocated 


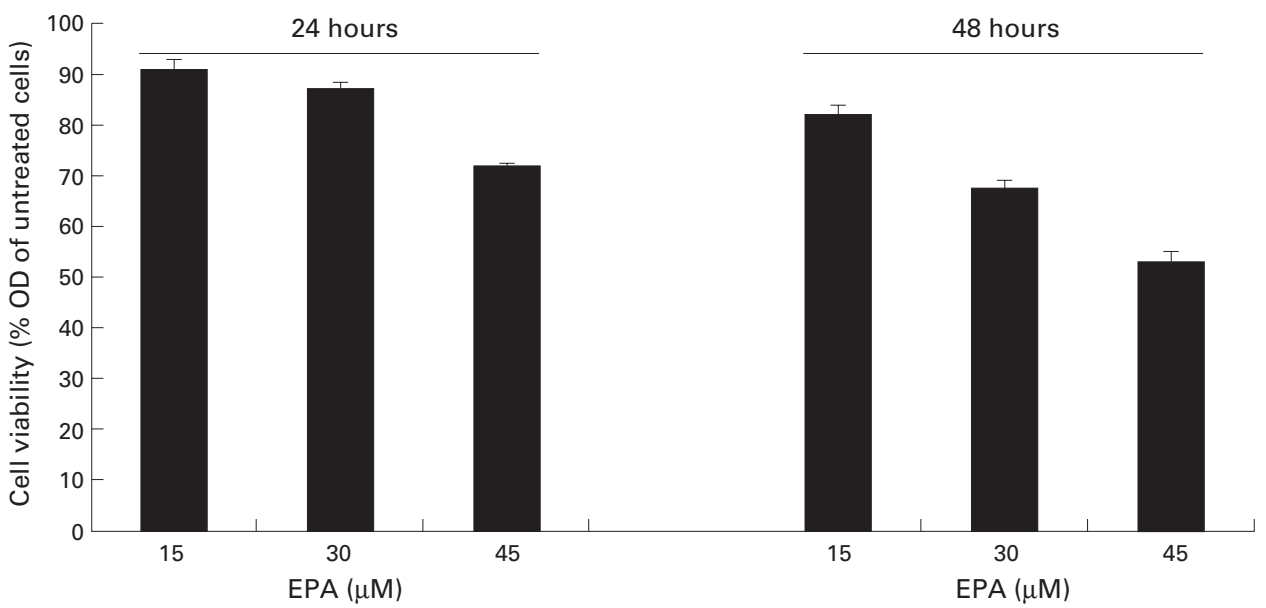

Figure 1 Adherent cell viability of HT29 cells following treatment with increasing concentrations of eicosapetaenoic acid (EPA 15-45 $\mu \mathrm{M}$ ) for 24 or 48 hours. Cell viability was assessed using the neutral red assay, and data are expressed as per cent of the optical density (OD) $)^{550 \mathrm{~mm}}$ of untreated control cultures (mean (SEM)). A minimum of $16 \mathrm{OD}^{550 \mathrm{~mm}}$ readings were taken for each treatment. EPA significantly reduced cell viability after 24 and 48 hours at all concentrations tested $(p<0.05)$ compared with untreated cells. Reduction in viable cell number was significantly associated with EPA treatment and time $(p<0.001)$.

among five equally spaced longitudinal compartments. A total of 20 crypts were analysed for each rat and data were expressed as total number of mitotic or apoptotic nuclei per crypt or crypt compartment. The origin of the samples was unknown to the histologist during the analysis.

MEASUREMENT OF EPITHELIAL GLUTATHIONE LEVELS

Intact colonic crypts were isolated from segments (approximately $4.0 \mathrm{~cm}$ ) of freshly excised colon. The segments were stirred gently for 30 minutes in PBS $\left(\mathrm{pH} 7.4 ; 0^{\circ} \mathrm{C}\right)$ containing EDTA ( $3 \mathrm{mM}$; BDH) and dithiothrietol (1.0 mM; Sigma), transferred to fresh buffer in polythene tubes $(25.0 \mathrm{ml})$, and shaken by hand to disaggregate the crypts. The denuded muscle tissues were discarded, the crypt suspension was pelleted by centrifugation $(1000 \mathrm{rpm})$, and the pellets $(500 \mu \mathrm{l})$ were frozen in liquid $\mathrm{N}_{2}$. Frozen pellets were later thawed and probe sonicated for 15 seconds prior to analysis. One subsample $(50 \mu \mathrm{l})$ was assayed for total protein (Micro-BCA Protein Assay Kit; Sigma) and a second $(200 \mu \mathrm{l})$ for total GSH (reduced and oxidised: $\mathrm{GSH}+\mathrm{GSSG}=\mathrm{GSX}$ ), as described above for HT29 cells.

\section{STATISTICAL ANALYSIS}

The significance of differences between the various treatment groups in this study was assessed by one way analysis of variance coupled with either Dunnet's test to compare means of treatments with those of untreated cultures or Tukey's test for comparison of individual means. In some experiments, two way analysis of variance using the general linear model was also used. Probability values of less than $5 \%(p<0.05)$ were regarded as significant. All analyses were carried out using the Minitab statistical package (State College, Pennsylvania, USA).

\section{Results}

EFFECTS OF EPA ON VIABILITY AND LIPID

COMPOSITION OF HT29 CELLS

Exposure of cells to EPA $(15,30$, and $45 \mu \mathrm{M})$ caused statistically significant reductions in cell viability compared with untreated cells at 24 and 48 hours after initial exposure (fig 1). Cell viability was inversely associated with increasing concentrations of EPA from 15 to $45 \mu \mathrm{M}$ at both time points $(p<0.05)$. Two way analysis of variance revealed a significant interaction between treatment with EPA and duration of exposure (24 or 48 hours). The percentage of EPA (C20:5) in the phospholipid fraction of HT29 cells treated with $15 \mu \mathrm{M}$ EPA for 24 hour rose from an initial value of $0.91 \%(n=2$; range $0.02 \%)$ to $18.2 \%(n=2$; range $1.76 \%)$. There was no further rise after treatment for 48 hours.

\section{INDUCTION OF CASPASE ACTIVITY}

Exposure of cells to EPA at 15, 30, and $45 \mu \mathrm{M}$ induced significant increases in DEVDase activity expressed as nmol $\mathrm{pNA} / \mathrm{h}$ per $10^{6}$ cells compared with untreated cultures after 24 and 48 hours of exposure (fig 2). DEVDase activity also increased significantly $(p<0.05)$ with increasing concentrations of EPA over the range $0-45 \mu \mathrm{M}$ and there was a significant interaction between treatment with EPA and time. DEVDase activity was found to be specific for caspase 3-like proteases as liberation of pNA after exposure to EPA at $45 \mu \mathrm{M}$ (10.8 (1.2) DEVDase units) was blocked by addition of a DEVD consensus caspase inhibitor to the reaction (3.0 (0.1) DEVDase units; $\mathrm{p}<0.05)$.

\section{CASPASE INHIBITION}

The adverse effects of EPA on HT29 cell viability were blocked or greatly diminished by cell permeable caspase inhibitors. Addition of $30 \mu \mathrm{M}$ EPA to HT29 cultures significantly reduced cell viability compared with untreated cultures at 48 hours $(\mathrm{p}<0.05)$ but when cells 


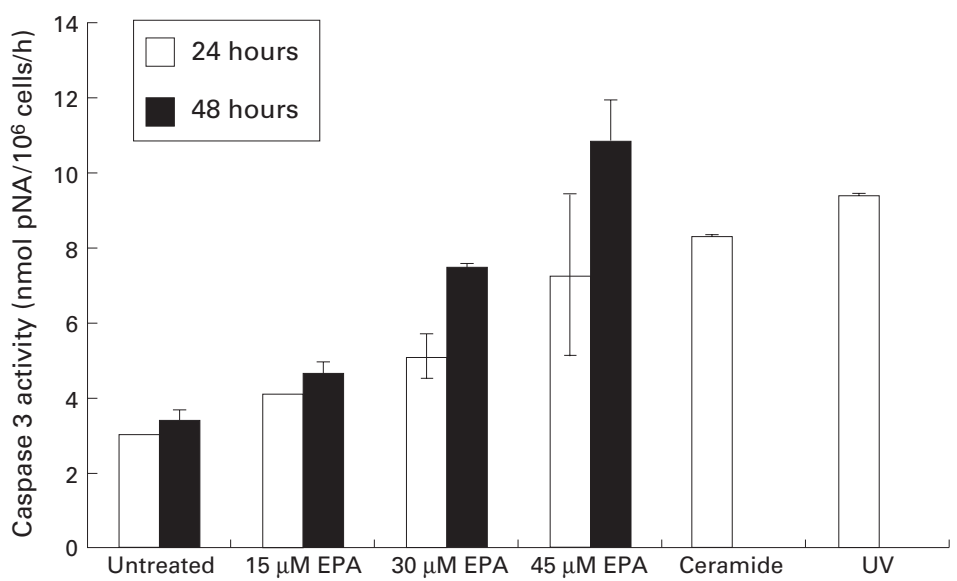

Figure 2 Activity of DEVDase caspases (chiefly caspase 3) in HT29 cells following treatment with increasing concentrations of eicosapetaenoic acid (EPA 15-45 $\mu \mathrm{M}$ ) for 24 or 48 hours. Positive control cells were also treated with $25 \mu M C_{2}$ ceramide (three hours) or $12000 \mathrm{~F} / \mathrm{cm}^{2}$ (UV, 30 minutes). Data are expressed as mean (SEM) $p N A$ liberated from a DEVDase consensus cleavage site per hour per $10^{6}$ cells of four samples per treatment group. Caspase activity was significantly higher in all EPA treated cells than in untreated cells after 24 and 48 hours $(p<0.05)$.

were treated with EPA and the broad range caspase inhibitors Z-VAD-FMK or BAF, cell viability was significantly higher than after treatment with EPA alone (table 1). The caspase 3 inhibitor Z-DEVD-FMK and the caspase 8 inhibitor IETD-CHO also significantly increased cell viability after 48 hours in the presence of $30 \mu \mathrm{M}$ EPA. There were no significant effects of any of the caspase inhibitors in the absence of EPA on cell viability of control cultures.

EFFECT OF ANTIOXIDANTS ON CELL VIABILITY IN THE PRESENCE OF EPA

Ebselen alone had no significant effect on the viability of HT29 cells but it proved highly effective at blocking the reductions in cell viability caused by treatment with EPA. Indeed there were no significant differences in the viability of cells cultured for 48 hours without EPA or with EPA $(15-45 \mu \mathrm{M})$ in the presence of ebselen (table 2). Similarly, U74389G had no effect on cell viability in the absence of EPA but at 48 hours cell numbers in cultures co-treated with U74389G and EPA at 15 and

Table 1 Survival of HT29 cells 48 hours after treatment with eicosapentaenoic acid (EPA) and/or one of a range of caspase inhibitors

\begin{tabular}{llr}
\hline Caspase inhibitor & $-E P A$ & $+E P A(30 \mu M)$ \\
\hline Control & $100(5)$ & $79.3(2.0)$ \\
Z-VAD-FAMK broad range caspases 1, 3, 4,7 & $105.0(5.3)$ & $101.8(4.4)$ \\
BAF broad range & $101.5(1.9)$ & $101.5(3.0)$ \\
Z-DEVD-FMK caspase 3 & $108.9(3.2)$ & $109.6(1.6)$ \\
IETD-CHO caspase 8 & $100.1(3.2)$ & $97.6(7.2)$
\end{tabular}

Results are expressed as percentage of control survival measured using neutral red vital dye inclusion into cells grown on 96 well plates. Data are given as mean (SEM).

BAF, Boc-Asp(Ome)-FMK.

Table 2 Effects of the three antioxidants ebselen ( $40 \mu \mathrm{M}), \mathrm{N}$-acetylcysteine (Nac $1 \mathrm{mM}$ ), and U74389G $(5 \mu M)$ on cell viability in cells treated with eicosapentaenoic acid (EPA $15-45 \mu M$ )

\begin{tabular}{lcrlr}
\hline & \multicolumn{1}{l}{ Control } & \multicolumn{1}{l}{ Ebselen } & Nac & \multicolumn{1}{l}{ U74389G } \\
\hline Control & $100(0.4)$ & $100.5(2.7)$ & $89.9(1.7)$ & $101.0(0.8)$ \\
EPA $(15 \mu \mathrm{M})$ & $78.1(0.4)$ & $100.0(0.6)$ & $84.0(1.7)$ & $96.9(2.4)$ \\
EPA $(30 \mu \mathrm{M})$ & $69.0(0.4)$ & $100.0(1.4)$ & $80.7(2.4)$ & $91.8(2.4)$ \\
EPA $(45 \mu \mathrm{M})$ & $54.9(0.3)$ & $99.1(1.2)$ & $76.5(0.5)$ & $86.3(0.6)$ \\
\hline
\end{tabular}

Cell viability was assessed using neutral red and data are expressed as mean (SEM) percentage relative to control of at least eight replicates.
$30 \mu \mathrm{M}$ were not significantly different from control values (table 2). Nac alone caused an approximate $10 \%$ reduction in viable cell number compared with untreated cells $(p<0.05)$ and was less effective than ebselen at blocking EPA associated reductions in cell viability (table 2). Nevertheless, viable cell numbers were significantly higher in all cultures co-treated with $\mathrm{Nac}$ and EPA after 48 hours than in corresponding EPA treated cultures $(\mathrm{p}<0.05)$.

EFFECTS OF GLUTATHIONE DEPLETION ON CELL VIABILITY IN THE PRESENCE OF EPA

Exposure to EPA alone caused a $20 \%$ reduction in the level of GSX in HT29 cells at 48 hours $(p<0.05)$ whereas treatment with BSO reduced GSX content of cells by approximately $90 \% \quad(\mathrm{p}<0.05)$. In the first 24 hours of $\mathrm{EPA}+\mathrm{BSO}$ exposure, cell viability was similar to that of cultures treated with EPA alone (data not shown) but there was an approximate 95\% reduction in viable cell number after 48 hours (fig 3). The major reductions in cell viability occurred within a window of approximately five hours (45-50 hours after initial exposure) where widespread cell death occurred rapidly in the whole population. Addition of the antioxidant ebselen to EPA+BSO treated cells restored cell viability at all concentrations of EPA tested $(p<0.05)$. However, the broad range caspase inhibitor Z-VAD-FMK, which inhibits caspases $1,3,4$, and 7 , was unable to block EPA induced cell death in the presence of $\mathrm{BSO}$, indicating that this gross cytotoxicity was not dependent on these caspases and therefore was probably necrotic rather than apoptotic.

EFFECTS OF FISH OIL AND BSO ON CRYPT CELL LIPID AND GLUTATHIONE CONTENT IN VIVO Consumption of the FO diet was associated with significant increases in levels of C20:5 in crypt cell phospholipids, and reductions in C18:2 and C20:4 in FO and FO-BSO animals $(\mathrm{p}<0.05)$ compared with those fed CO (table 3). The C20:3 content of phospholipids was also reduced in FO fed animals $(p<0.05)$. There was no significant effect of BSO on crypt cell lipids within the dietary groups. After 24 hours total levels of GSH in isolated colonic crypts from animals fed CO (0.20 (0.04) $\mathrm{GSH} / \mathrm{mg}$ protein) and $\mathrm{FO}(0.18(0.02) \mathrm{mg}$ $\mathrm{GSH} / \mathrm{mg}$ protein) were not significantly different but both differed significantly $(p<0.05)$ from animals treated with BSO (CO-BSO 0.08 (0.01); FO-BSO 0.07 (0.02) mg GSH/mg protein). At 48 hours and one week there were no further effects of treatment on GSH levels in crypts.

EFFECTS OF LIPID AND BSO ON CRYPT CELL MITOSIS AND APOPTOSIS

Total numbers of mitotic cells per crypt were approximately $30 \%$ lower in the distal colon of animals fed the FO diet compared with those fed CO after 24 hours, 48 hours, and one week $(\mathrm{p}<0.001)$ (fig 4$)$. To put this into perspective it should be noted that a difference in mitotic frequency of this magnitude would equate to a difference in mitotic rate of approximately 


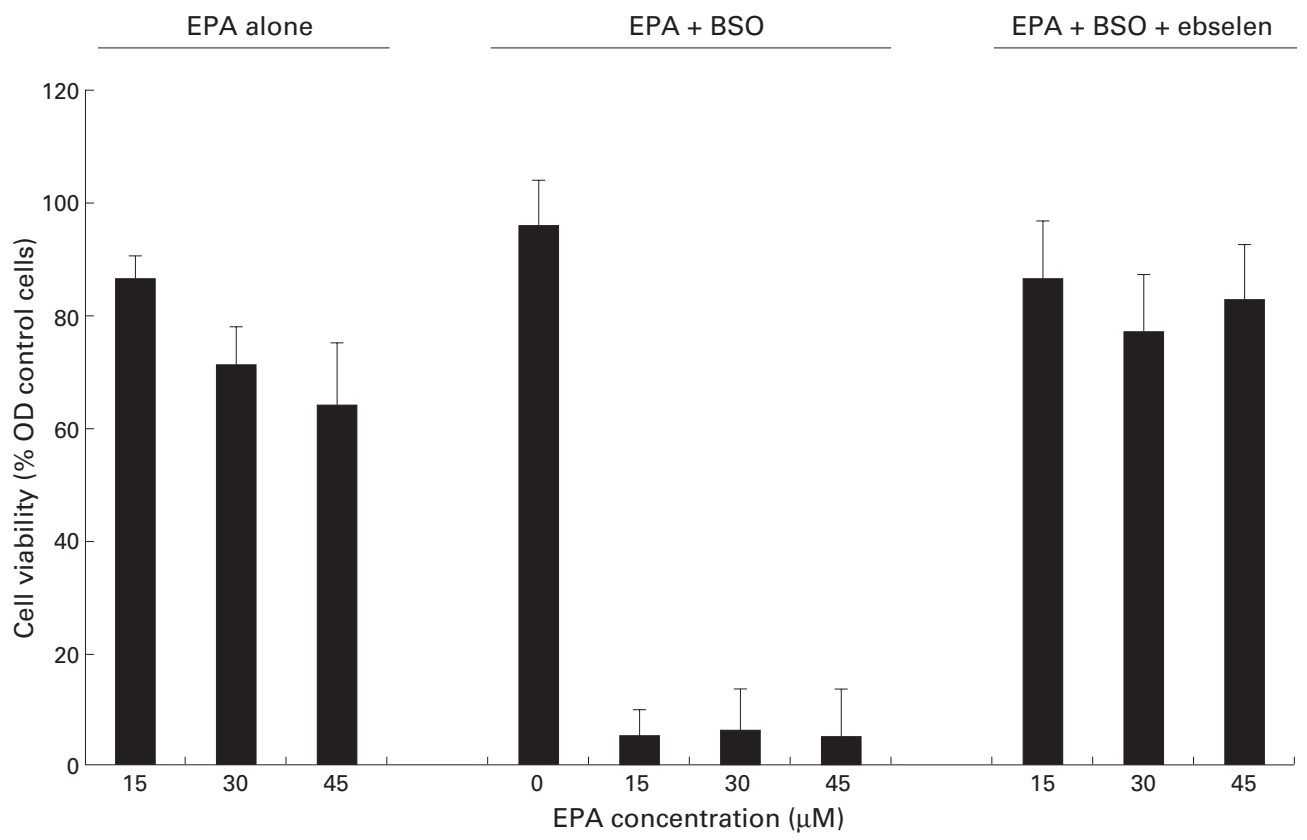

Figure 3 Adherent HT29 cell viability following treatment with eicosapetaenoic acid (EPA) (15-45 $\mu M), E P A+100 \mu M$ buthionine sulphoximine (BSO), or EPA $+B S O+40 \mu M$ ebselen for 48 hours. Cell viability was assessed using the neutral red assay, and data are expressed as mean (SEM) per cent of the optical density (OD) $)^{\text {s5onin }}$ of untreated control cultures. $A$ minimum of eight $O D^{5 S s_{n u m}}$ readings were taken for each treatment. EPA significantly reduced cell viability after 48 hours at all concentrations tested $(p<0.05)$ compared with untreated cells. BSO alone did not significantly affect cell viability. Exposure to EPA $(15-30 \mu M)+B S O$ significantly reduced cell viability $(p<0.05)$ but addition of ebselen to EPA $+B S O$ cultures significantly increased cell viability $(p<0.05)$.

three cell divisions per crypt per hour. ${ }^{28}$ Assuming a crypt density of approximately 300 crypts $/ \mathrm{mm}^{2}$, this would lead to a deficit in crypt cell production in rats fed $\mathrm{FO}$ of about 900 cell divisions $/ \mathrm{mm}^{2}$ of mucosal surface per hour.

There were no significant additional effects of BSO treatment on levels of mitosis in either $\mathrm{CO}$ or $\mathrm{FO}$ fed rats. In all treatment groups, crypt cell mitosis was maximal within the basal zone, declined in zones 2 and 3, and was entirely absent in the superficial zones 4 and 5 (data not shown). There was no significant difference in crypt length between $\mathrm{CO}$ and FO fed groups at 24 hours. However, after seven days mean crypt length in FO fed rats (243 $\mu \mathrm{M})$ was significantly lower than that of $\mathrm{CO}$ fed rats $(262 \mu \mathrm{M} ; \mathrm{p}<0.05)$ and both BSO treated groups had significantly shorter crypts than their respective controls at this time (about 3\%; $\mathrm{p}<0.05)$. When data for mitotic cells per crypt were normalised using crypt length as an index of cell number, and re-expressed as mitotic cells per unit crypt length, the distribution of differences between groups remained essentially unchanged and one way analysis of variance confirmed that levels of mitosis were significantly lower in FO and FO-BSO rats than in $\mathrm{CO}$ or CO-BSO rats, respectively $(\mathrm{p}<0.05)$.

Apoptotic nuclei were rarely seen $(<0.05$ apoptotic cells per crypt) in the distal colonic tissue of animals fed the CO diet (fig 5). Treatment of CO fed rats with BSO significantly increased levels of crypt cell apoptosis compared with those fed only CO $(p<0.05)$ but there was a greater increase associated with consumption of the FO diet $(\mathrm{p}<0.001)$. At each time point, significantly higher levels of apoptosis were found in the colonic crypts of FO fed animals than in CO or CO-BSO animals $(p<0.05)$. Treatment with $5 \mathrm{mM}$ BSO in the drinking water of $\mathrm{FO}$ fed animals (FO-BSO) further increased levels of crypt cell apoptosis compared with the FO group $(\mathrm{p}<0.05)$, and there was a trend towards an interaction between $\mathrm{BSO}$ and the FO diet, and levels of apoptosis $(\mathrm{p}<0.08)$. Apoptotic nuclei were found throughout the crypt. When the data were normalised using crypt length as an index of cell number, and re-expressed as apoptotic nuclei per unit crypt length, the distribution of differences between groups remained essentially unchanged.

Table 3 Effects of chronic intracellular glutathione (GSX) depletion and dietary lipid (corn oil (CO) and fish oil (FO)) on the phospholipid composition of isolated colonic crypts after one week

\begin{tabular}{lllllllrrr}
\hline & C16:0 & C18:0 & C18:1 n-9 & C18:1n-7 & C18:2 n-6 & C20:3 n-6 & C20:4n-6 & C20:5 n-3 \\
\hline CO & $17.92(1.55)$ & $11.15(0.87)$ & $14.66(1.71)$ & $4.56(0.43)$ & $18.55(2.33)$ & $1.98(1.13)$ & $13.98(1.93)$ & $0.00(0.0)$ \\
CO/BSO & $18.89(1.59)$ & $11.07(1.08)$ & $14.19(1.52)$ & $4.27(0.61)$ & $19.33(2.81)$ & $3.27(3.43)$ & $13.39(1.94)$ & $0.00(0.0)$ \\
FO & $17.23(1.65)$ & $13.55(0.91)$ & $17.09(0.48)$ & $5.56(0.23)$ & $8.67^{\star}(0.70)$ & $0.57^{\star}(0.77)$ & $10.21^{\star}(0.64)$ & $9.81^{\star}(0.58)$ \\
FO/BSO & $16.53(1.93)$ & $11.21(3.16)$ & $15.24(3.12)$ & $4.1(2.41)$ & $8.44^{\star}(1.97)$ & $0.30^{\star}(0.67)$ & $9.81^{\star}(2.02)$ & $10.2^{\star}(1.89)$ \\
\hline
\end{tabular}

Results are mean (SEM) percentage of polar lipids extracted from five animals.

${ }^{\star} \mathrm{p}<0.05$, significantly different from the $\mathrm{CO}$ and $\mathrm{CO}-$ buthionine sulphoximine (BSO) group.

Only the major fatty acids found in samples are shown and thus values do not add up to $100 \%$. Minor lipids (not shown) remained essentially unchanged by treatment. 

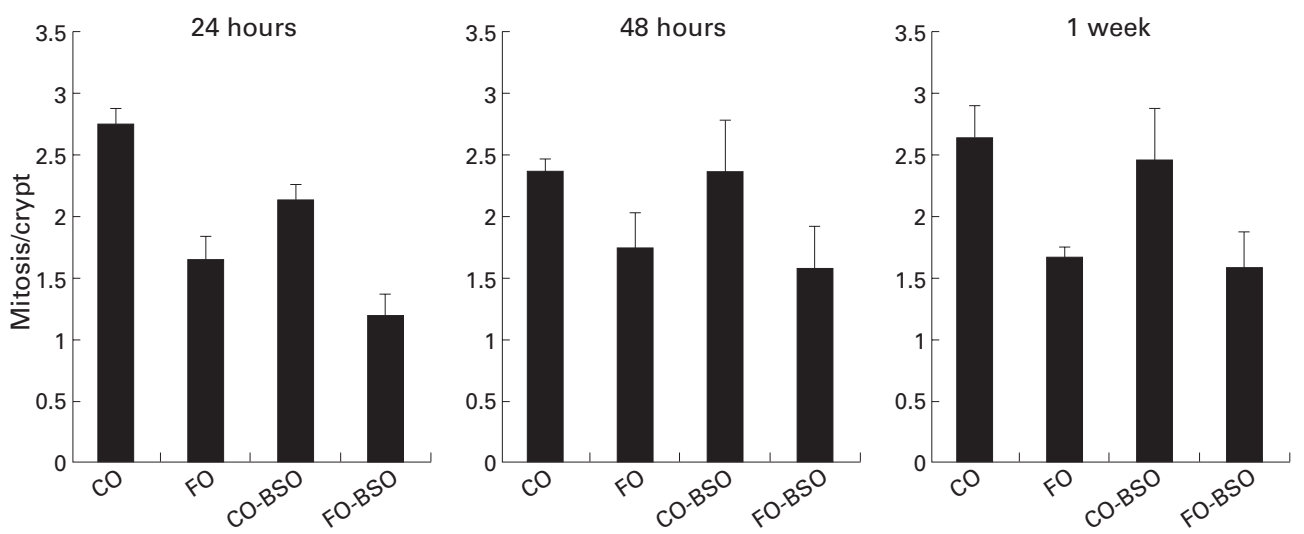

Figure 4 Mitotic cells per crypt expressed as mean (SEM) in crypts isolated from the distal colon of rats given corn oil (CO) or fish oil (FO) in the diet with or without $5 \mathrm{mM}$ buthionine sulphoximine (BSO) in drinking water. There was a significant reduction in mitotic cells/crypt associated with $F O$ consumption at all time points $(p<0.001)$ but no significant effect of BSO in the drinking water.
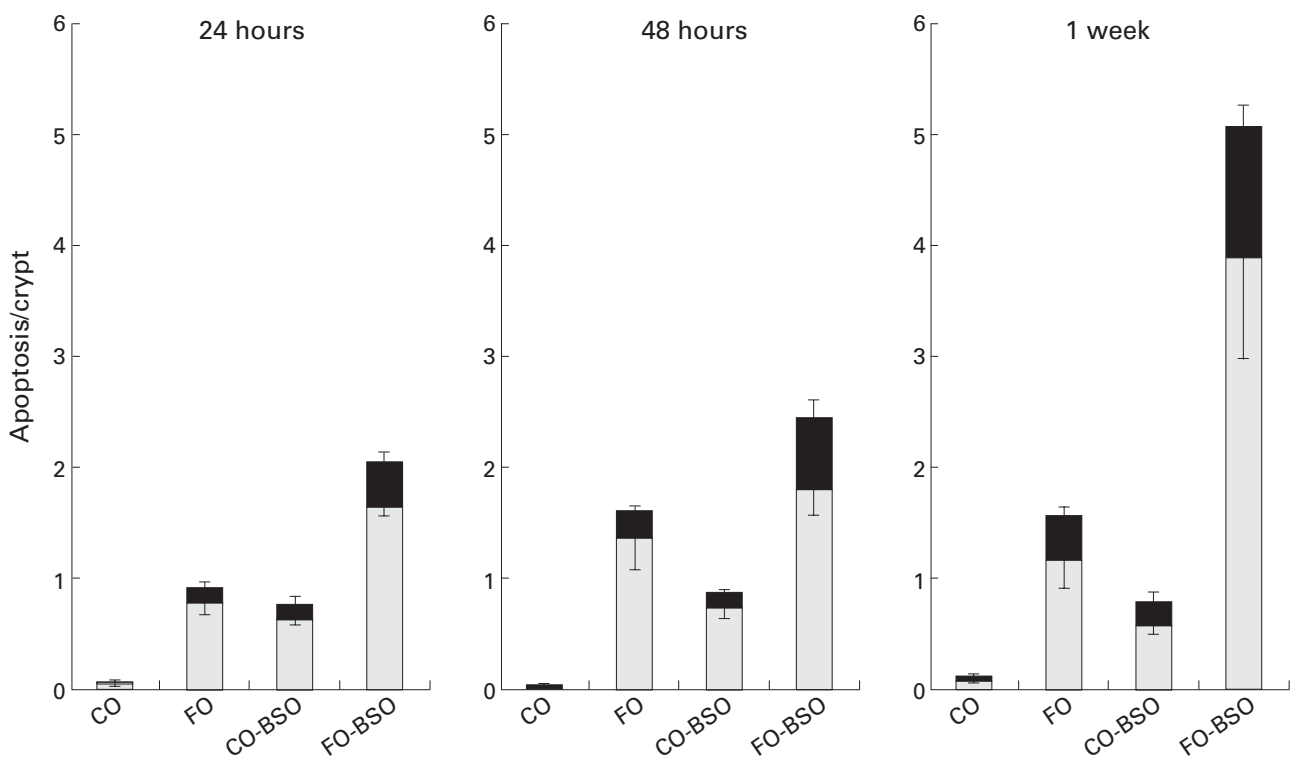

Figure 5 Apoptotic cells per crypt expressed as mean (SEM) in crypts isolated from the distal colon of rats given corn oil (CO) or fish oil (FO) in the diet with or without $5 \mathrm{mM}$ buthionine sulphoximine (BSO) in the drinking water. The total number of apoptotic cells is represented by total column height; the number in the top $40 \%$ of the crypt is represented in black and in the bottom $60 \%$ as the shaded region. Both FO and BSO significantly increased the total number of apoptotic cells/crypt at all time points $(p<0.001)$.

\section{Discussion}

Unlike other non-specific forms of cell death, apoptosis is fundamental to the maintenance of tissue homeostasis. ${ }^{29}$ Recent work suggests that failure of the apoptotic machinery leads to an increased frequency of mutation, both in vitro and in the mucosal epithelium in vivo, and this effect favours the clonogenic survival of malignant cells. ${ }^{30}$ Conversely, we have previously observed that increased rates of crypt cell apoptosis following consumption of fish oil are associated with a reduction in chemically induced aberrant crypt foci. ${ }^{8}$ It is now recognised that both $x$ rays and chemotherapeutic drugs act by inducing cell suicide. Other less drastic means of manipulating apoptosis in the replicating region of the crypt may prove to be of practical value in the prevention or treatment of colorectal disease. ${ }^{31}$

In the present study we first used an in vitro model system to study the impact of an n-3 PUFA on the growth and survival of a human colorectal cancer cell line. Incorporation of
EPA into the cellular lipids of HT29 cells was associated with a reduction in adherent cell number and a dose dependent increase in caspase 3 activity in adherent cells. The importance of the caspases in the onset of cell death induced by EPA was confirmed by the fact that both broad range caspase inhibitors and specific inhibitors of caspase 8 and caspase 3 eliminated the reduction in adherent cell number. Caspase activity is an essential characteristic of apoptosis. The precise roles and interactions of the different members of the caspase family are still being defined but it is generally accepted that caspase 3 is the major downstream effector caspase which cleaves major cell components during apoptosis. Caspase 8 on the other hand is an initiator caspase forming part of the tumour necrosis factor $\alpha /$ Fas associated TRADD or FADD pathway. ${ }^{32}$ Chemotherapeutic drugs have been shown to enhance both Fas receptor and Fas ligand expression by tumour cells. The contribution of this pathway to induction of apoptosis by 
these drugs remains controversial ${ }^{33-35}$ but the present data suggest that incorporation of EPA into the membrane lipid pool may initiate apoptosis through a Fas related mechanism involving caspase 8 .

Having shown that induction of cell death in HT29 cells by EPA occurs through caspase dependent apoptosis we also established that it was initiated via a mechanism involving reactive oxygen species. Three antioxidants with differing properties were chosen to explore the relationship between apoptosis and the redox conditions of the cell. Ebselen, the activity of which depends on its ability to mimic GSH peroxidase activity by catalytically reducing $\mathrm{H}_{2} \mathrm{O}_{2}$ or lipid hydroperoxides in the presence of thiols such as GSH, ${ }^{36}{ }^{37}$ was found to be the most effective at blocking EPA induced reductions in attached cell number. Addition of the lazaroid U74389 or Nac to the medium also protected HT29 cells from the apoptosis inducing effects of EPA, although to a lesser extent. U74389G is a potent lipid soluble inhibitor of membrane lipid peroxidation $^{38} 39$ whereas the antioxidant properties of Nac stem from its hydrolysis after incorporation into the cell to form cysteine, thereby increasing the availability of this amino acid for GSH neosynthesis. There is also evidence that $\mathrm{Nac}$ can exert direct free radical scavenging activity within the cytoplasm. ${ }^{40}$ Taken together these data strongly suggest that lipid peroxidation and the consequent changes in the redox state of the cell play a major role in EPA induced death of HT29 cells. Our data are consistent with a number of other studies on induction of apoptosis by PUFA in human cancer cells ${ }^{17}$ but they provide an interesting contrast with the findings of Chinery and colleagues $^{21}$ who showed that in two other human colorectal cancer cell lines, apoptosis was increased by a reduction in intracellular hydrogen peroxide levels induced by exposure to antioxidants.

Having established the ability of antioxidants to regulate apoptosis in colorectal cells, we went on to explore the role of endogenous antioxidant mechanisms mediated via GSH metabolism. Treatment with $30 \mu \mathrm{M}$ EPA alone reduced the GSH content of HT29 cells by approximately $20 \%$ after 48 hours. The mechanism underlying this effect was not addressed but it may have been due to the increase in lipid peroxidation causing the rate of GSH utilisation to exceed that of neosynthesis. Treatment of cells with the $\gamma$-glutamylcysteine synthetase inhibitor BSO for 48 hours in the absence of EPA reduced their GSH content by approximately $90 \%$ but with no significant effect on viable cell numbers. In contrast, when cells grown with EPA at the relatively low concentration of $15 \mu \mathrm{M}$ were exposed to BSO, viable adherent cell numbers were reduced by approximately $95 \%$ relative to controls. This drastic decline in cell viability was largely prevented by addition of ebselen to the incubations containing EPA and BSO, and cell numbers returned to approximately $85 \%$ of untreated control cultures. These findings are consistent with the hypothesis that while the presence of EPA in the cellular lipid pool provides pro-oxidant conditions that favour apoptosis, depletion of cellular GSH greatly increases the vulnerability of cells, leading to frank cytotoxicity and necrosis. ${ }^{41}$ There is evidence from other systems to show that cell death switches from apoptosis to necrosis under conditions of GSH depletion. ${ }^{42}$

As with cells exposed to EPA in vitro, consumption of FO by rats led to prompt incorporation of EPA into the crypt cell phospholipids and a decline in the levels of linoleic acid (C18:2 n-6) and arachidonic acid (C20:4; n-6) compared with rats fed CO. These changes were associated with a reduction in crypt cell proliferation and an increase in apoptosis in the distal colon compared with animals fed diets containing CO. This is consistent with our own previous work and that of others showing that n-3 PUFA modulate crypt cell kinetics in animal models. ${ }^{43}{ }^{44}$ Consumption of the FO diet in the absence of BSO did not significantly affect levels of mucosal GSH but treatment with BSO reduced the GSH content of crypts by $60-70 \%$. There was no statistically significant effect of BSO treatment on crypt cell mitosis and no gross evidence of damage to the mucosa. However, the frequency of crypt cell apoptosis was significantly increased in both $\mathrm{CO}$ and FO fed rats treated with $\mathrm{BSO}$, and the highest level of apoptosis was observed in BSO treated rats fed FO. These findings appear consistent with the in vitro study. Evidently, pro-oxidant conditions favour crypt cell apoptosis in vivo and the effects of EPA and GSH depletion can combine to provide the crypt epithelium with a stronger pro-apoptotic signal. However, unlike the in vitro model system, there was no evidence of gross necrotic changes in the GSH depleted colonic mucosa.

Apoptotic nuclei were rare at any position in the colonic crypts of animals fed CO alone but there was a substantial increase in cell death in animals treated with the carcinogen DMH. In both $\mathrm{CO}$ and FO fed rats, the apoptotic nuclei induced by DMH are confined almost exclusively to the basal half of the crypt $^{8}$ whereas the apoptotic events associated with the combined effects of FO and BSO were distributed more evenly throughout the crypts (fig 5). A similar distribution of apoptotic nuclei was reported recently in patients with familial adenomatous polyposis after treatment with sulindac, and this was associated with a statistically significant reduction in polyp number. ${ }^{45}$

Our findings have established, for the first time to our knowledge, that incorporation of an n-3 PUFA induces caspase activity in human adenocarcinoma cells and promotes cell death via a caspase dependent mechanism which begins before any morphological evidence of apoptosis. The mechanism appears to be dependent on modulation of cellular redox balance following incorporation of EPA into cellular lipids. Crucially, we have obtained evidence to suggest that our in vitro model is of direct relevance to the effects of dietary lipids on the intact colorectal mucosa in an animal model. Incorporation of EPA into crypt 
epithelial cell lipids of the rat leads to apoptosis through a mechanism which also appears sensitive to redox balance. There is substantial interest in the potential pathological effects of peroxidised lipids and other sources of oxidative stress in the gut. ${ }^{46}$ However, the present study, coupled with previous work showing that consumption of fish oil suppresses the appearance of neoplastic changes after treatment with $\mathrm{DMH},{ }^{8}{ }^{44}$ adds further weight to the growing evidence that manipulation of cellular lipids has potential benefits in the prevention and treatment of colorectal cancer. ${ }^{31}$

The authors wish to thank Simon Deakin and Valerie Russel for technical assistance. This work was supported by the Biotechnology and Biological Sciences Research Council, UK.

1 Piazza GA, Rahm AK, Finn TS, et al. Apoptosis primarily accounts for the growth-inhibitory properties of sulindac metabolites and involves a mechanism that is independen of cyclooxygenase inhibition, cell cycle arrest, and p53 induction. Cancer Res 1997;57:2452-9.

2 Takayama T, Katsuki S, Takahashi Y, et al. Aberrant crypt foci of the colon as precursors of adenoma and cancer. $N$ Engl f Med 1998;339:1277-84.

3 Giardiello FM, Offerhaus JA, Tersmette AC, et al. Sulindac induced regression of colorectal adenomas in familial adenomatous polyposis: evaluation of predictive factors. Gut 1996;38:578-81.

4 Begin ME, Das UN, Ells G, et al. Selective killing of human cancer cells by polyunsaturated fatty acids. Prostaglandins cancer cells by polyunsatura
Leukot Med 1985;19:177-86.

5 Lhuillery C, Cognault S, Germain E, et al. Suppression of the promoter effect of polyunsaturated fatty acids by the absence of dietary vitamin $\mathrm{E}$ in experimental mammary carcinoma. Cancer Lett 1997;114:233-4.

6 Gonzalez MJ, Schemmel RA, Gray JI, et al. Effect of dietary fat on growth of MCF-7 and MDA-MB231 human breas carcinomas in athymic nude mice: relationship between carcinoma growth and lipid peroxidation product levels. Carcinogenesis 1991;12:1231-5.

7 Anti M, Marra G, Armelao F, et al. Effect of omega-3 fatty acids on rectal mucosal cell proliferation in subjects at risk for colon cancer. Gastroenterology 1992;103:883-91.

8 Latham P, Lund EK, Johnson IT. Dietary n-3 PUFA increases the apoptotic response to 1,2- dimethylhydrazine, reduces mitosis and suppresses the induction of carcinogenesis in the rat colon. Carcinogenesis 1999;20:645-50.

9 Chang W, Chapkin RS, Lupton JR. Predictive value of proliferation, differentiation and apoptosis as intermediate markers for colon tumorigenesis. Carcinogenesis 1997;18: markers

10 Ruemmele FM, Dionne S, Qureshi I, et al. Butyrate mediates Caco-2 cell apoptosis via up-regulation of pro-apoptotic BAK and inducing caspase-3 mediated cleavage of poly-(ADP- ribose) polymerase (PARP). Cell Death Differ 1999;6:729-35.

11 Droin N, Dubrez L, Eymin B, et al. Upregulation of CASP genes in human tumor cells undergoing etoposide-induced apoptosis. Oncogene 1998;16:2885-94.

12 Grossmann J, Mohr S, Lapentina EG, et al. Sequential and rapid activation of select caspases during apoptosis of normal intestinal epithelial cells. Am f Physiol 1998;274 G1117-24.

13 Chan SL, Mattson MP. Caspase and calpain substrates: Roles in synaptic plasticity and cell death. $\mathcal{F}$ Neurosci Res 1999;58:167-90.

14 Clarke RG, Lund EK, Latham P, et al. Effect of eicosapentaenoic acid on the proliferation and incidence of apoptosis
in the colorectal cell line HT29. Lipids 1999;34:1287-95.

15 Williams AC, Hague A, Elder DJ, et al. In vitro models for studying colorectal carcinogenesis: cellular and molecular events including APC and Rb cleavage in the control of proliferation, differentiation and apoptosis. Biochim Biophys Acta 1996;1288:F9-19.

16 Sagar PS, Das UN. Cytotoxic action of cis-unsaturated fatty acids on human cervical carcinoma (HeLa) cells in vitro. Prostaglandins Leukot Essent Fatty Acids 1995;53:287-99.

17 Hawkins RA, Sangster K, Arends MJ. Apoptotic death of pancreatic cancer cells induced by polyunsaturated fatty acids varies with double bond number and involves an oxidative mechanism. F Pathol 1998;185:61-70.

18 Gonzalez MJ, Schemmel RA, Dugan L Jr, et al. Dietary fish oil inhibits human breast carcinoma growth: a function of increased lipid peroxidation. Lipids 1993;28:827-32.

19 Bagchi D, Carryl OR, Tran MX, et al. Acute and chronic stress-induced oxidative gastrointestinal mucosal injury in rats and protection by bismuth subsalicylate. Mol Cell Biochem 1999;196:109-16.
20 Benard O, Madesh M, Anup R, et al. Apoptotic process in the monkey small intestinal epithelium: I. Association with glutathione level and its efflux. Free Radic Biol Med 1999;26:245-52.

21 Chinery R, Brockman JA, Peeler MO, et al. Antioxidants enhance the cytotoxicity of chemotherapeutic agents in colorectal cancer: a p53-independent induction of p21WAF1/CIP1 via C/EBPbeta. Nat Med 1997;3:123341.

22 Chinery R, Beauchamp RD, Shyr Y, et al. Antioxidants reduce cyclooxygenase-2 expression, prostaglandin production, and proliferation in colorectal cancer cells. Cancer Res 1998;58:2323-7.

23 Marangoni F, Angeli MT, Colli S, et al. Changes of n-3 and $\mathrm{n}-6$ fatty acids in plasma and circulating cells of normal subjects, after prolonged administration of 20:5 (EPA) and 22:6 (DHA) ethyl esters and prolonged washout. Biochim Biophys Acta 1993;1210:55-62.

24 Sakamoto K, Venkatraman G, Shamsuddin AM. Growth inhibition and differentiation of HT-29 cells in vitro by inositol hexaphosphate (phytic acid). Carcinogenesis 1993; 14:1815-19.

25 Bligh E, Dyer W. A rapid method of total lipid extraction and purification. The National Research Council of Canada $1959 ; 37$.

26 Brown JC, Hughes DA, Stanley JC. Use of argentation TLC with GC to resolve C18:1 fatty acid isomers in test and commercial spreads. Biochem Soc Trans 1998;26:S176.

27 Baker MA, Cerniglia GJ, Zaman A. Microtiter plate assay for the measurement of glutathione and glutathione disulfide in large numbers of biological samples. Anal Biochem 1990;190:360-5.

28 Matthew JA, Pell JD, Prior A, et al. Validation of a simple technique for the detection of abnormal mucosal cell replitechnique for the detection of abnormal mucosal cell

29 Hengartner MO. The biochemistry of apoptosis (in process citation). Nature 2000;407:770-6.

30 Toft NJ, Winton DJ, Kelly J, et al. Msh2 status modulates both apoptosis and mutation frequency in the murine small intestine. Proc Natl Acad Sci USA 1999;96:3911-15.

31 Das UN, Madhavi N, Sravan Kumar G, et al. Can tumour cell drug resistance be reversed by essential fatty acids and their metabolites? Prostaglandins Leukot Essent Fatty Acids 1998;58:39-54.

32 Cohen GM. Caspases: the executioners of apoptosis. Biochem f 1997;326:1-16.

33 Houghton JA. Apoptosis and drug response. Curr Opin Oncol 1999;11:475-81.

34 Micheau O, Solary E, Hammann A, et al. Fas ligandindependent, FADD-mediated activation of the Fas death pathway by anticancer drugs. F Biol Chem 1999;274:798792.

35 Wesselborg S, Engels IH, Rossmann E, et al. Anticancer drugs induce caspase-8/FLICE activation and apoptosis in the absence of CD95 receptor/ligand interaction. Blood 1999;93:3053-63.

36 Muller A, Cadenas E, Graf P, et al. A novel biologically active seleno-organic compound-I. Glutathione peroxidase-like activity in vitro and antioxidant capacity of PZ 51 (Ebselen). Biochem Pharmacol 1984;33:3235-9.

37 Muller A, Gabriel H, Sies H. A novel biologically active selenoorganic compound-IV. Protective glutathionedependent effect of PZ 51 (ebselen) against ADP-Fe induced lipid peroxidation in isolated hepatocytes. Biochem Pharmacol 1985;34:1185-9.

38 Hinzmann JS, McKenna RL, Pierson TS, et al. Interaction of antioxidants with depth-dependent fluorescence quenchers and energy transfer probes in lipid bilayers. quenchers and energy transfer prob

39 Kalra J, Mantha SV, Kumar P, et al. Protective effects of lazaroids against oxygen-free radicals induced lysosomal damage. Mol Cell Biochem 1994;136:125-9.

40 Aruoma OI, Halliwell B, Hoey BM, et al. The antioxidant action of $\mathrm{N}$-acetylcysteine: its reaction with hydrogen peroxide, hydroxyl radical, superoxide, and hypochlorous acid. Free Radic Biol Med 1989;6:593-7.

41 Voehringer DW. BCL-2 and glutathione: alterations in cellular redox state that regulate apoptosis sensitivity. Free Radic Biol Med 1999;27:945-50.

42 Hampton MB, Fadeel B, Orrenius S. Redox regulation of the caspases during apoptosis. Ann N Y Acad Sci 1998;854: 328-35.

43 Pell JD, Brown JC, Johnson IT. Polyunsaturated fatty acids of the $n-3$ series influence intestinal crypt cell production in rats. Carcinogenesis 1994;15:1115-19.

44 Chang WL, Chapkin RS, Lupton JR. Fish oil blocks azoxymethane-induced rat colon tumorigenesis by increasing cell differentiation and apoptosis rather than decreasing cell proliferation. I Nutr 1998;128:491-7.

45 Keller JJ, Offerhaus GJ, Polak M, et al. Rectal epithelial apoptosis in familial adenomatous polyposis patients treated with sulindac. Gut 1999;45:822-8.

46 Aw TY. Molecular and cellular responses to oxidative stress and changes in oxidation-reduction imbalance in the intestine. Am $\mathcal{F}$ Clin Nutr 1999;70:557-65. 